\title{
Stormwater Storage Pond Configuration for Hydropower Solutions: Adaptation and Optimization
}

\author{
Helena M. Ramos ${ }^{1}$, Kaloyan N. Kenov ${ }^{1} \&$ Baptiste Pillet $^{2}$ \\ ${ }^{1}$ IST, Department of Civil Engineering, Lisbon, Portugal \\ ${ }^{2}$ Engineering School Centrale Nantes, Nantes Cédex, France \\ Correspondence: Helena M. Ramos, IST, Department of Civil Engineering, Av. Rovisco Pais, 1049-001, Lisbon, \\ Portugal. E-mail: hramos.ist@gmail.com; hr@civil.ist.utl.pt
}

Received: May 16, 2012 Accepted: June 26, 2012 Online Published: July 16, 2012

doi:10.5539/jsd.v5n8p27 URL: http://dx.doi.org/10.5539/jsd.v5n8p27

\begin{abstract}
The purpose of this paper is to analyze different storage pond configurations used to manage the water inflow from storm events and to establish a methodology to optimize the energy production using this water. The case study area is a catchment based on the Alcântara zone, in Lisbon, Portugal. This is an urban area, which faces severe occurrences of storm events. These events are caused by a non-efficient drainage system, and the proximity of the river and the sea, which cannot handle large storm event inflows. Due to climate change effects, the storm rainfall hyetographs are modified and runoff in this urban area has increased for the last decades causing major inundations.

The Danish Hydraulic Institute (DHI) MIKE BASIN (MB) and Bentley PondPack software are used to define solutions for this case study by embodying some of the Alcântara's catchment characteristics. Different relevant components used to create the models are presented. In order to model completely the studied area, several physical elements such as reservoirs or hydropower plants are included. The Nedbør-Afstrømnings-Model (NAM model) is also presented. It is a rainfall-runoff simulator, included in DHI MB, which can create runoff time series from rainfall time series. The methodologies used to optimize energy production in each of case studies developed are detailed. Results are presented showing that some ponds configurations permit to produce more energy than others and the production of energy can be maximized by optimizing the hydropower production target demand.
\end{abstract}

Keywords: storm events, energy production, retention ponds management, optimization

\section{Introduction}

The goal of this paper is to show how the Danish Hydraulic Institute (DHI) MIKE BASIN (MB) software can be used as a Decision Support System (DSS) tool to model and analyze flood management practices by using retention ponds to prevent the occurrence of inundation events and to optimize energy production from stormwater in an urban setting. MB is a product developed by DHI. It couples Arc GIS with hydrologic and hydraulic modelling components to provide catchment-scale solutions at the desired level of detail. It also includes simulation and optimization tools.

PondPack, developed by Bentley, is used to design retention ponds dimensions in order to improve the results obtained with MB. With both software suits, optimal configurations to produce energy are analyzed for each of the considered study cases: a single pond to manage all the stormwater inflow; two ponds in parallel (each retention pond is routing half of the inflow); two ponds in series with a single inflow upstream of the first pond; and two ponds in series with two catchments generating each one the half of the total inflow (one catchment is defined upstream of each pond). In each case, the total amount of the runoff generated by the single catchment or by both catchments is the same.

\section{Brief Background}

Water is more than ever an important topic of consideration. With the demographic growth and climate changes, the question of the regional water allocation is crucial. Climate changes have consequences on rainfall hyetographs and on runoff generated in catchments (Bethers \& Sennikovs, 2009). River flows are modified 
which can be problematic in regions, such as Hoang Long River, where studies are carried out to handle storm events (Tu \& Ting sanchali, 2010).

Decision Support Systems (DSS) are developed to serve the management and operations and to help to make decisions, which may be rapidly changing and not easily specified in advance. DSS is the costless way to identify and iterate feasible solutions to problematic situations. By modelling situations or configurations, simulations and tests can help to make decisions. In hydrology and hydraulics, it is an important tool which permits to develop solutions with low costs Orlob (1992).

DSS which includes hydrology characteristics such as rainfall or snow has to provide a tool which permits to determinate runoff generated from such hydrological events. A model used by DHI is the Nedbør-Afstrømnings-Model (NAM model). It permits to make the link between hydrological conditions and the behavior of the catchment which manages this water (King, 2004). In a realistic case, the NAM model has to be calibrated to generate runoff and outflow as close to the observed ones as possible (DHI, 2008). When a decision has to be taken, it is important to be able to model catchments or the behavior of rivers and to get results similar to those observed in reality. This calibration permits to validate the model and to be sure that it can be used to solve the problem at hand (Giang \& Phuong, 2010).

An important component used to manage overland flow is reservoirs. There are several types of reservoirs, such as retention ponds or operated reservoirs, and they are the common solution to handle water management and water allocation issues (APFM et al., 2008). According to water users which are provided with water from the ponds, the inflow and the outflow limitations should be carefully considered, thus ensuring the proper dimensions of ponds. It is possible to optimize pond dimensions by estimating storage volume requirements (Storage volume requirement). It is essential to not overestimate size of the pond and to not underestimate it, which may cause overflows and flood events (Meadows et al., 2002).

Reservoirs can be operated in order to manage overland flow according to the amount of inflow, the outflow requirements or the needs of water users. Yeh (1985) and Oliveira and Loucks (1997) provide a description of several possible approaches. Reservoir model are generally included in DSS models in order to take into account their influence (Wurbs, 2005). A way to solve the problem with pond dimensions is also to optimize the ponds operating rules in spite of optimizing their dimensions. According to the current situation (amount of water from the overland inflow, users' needs), policies used to manage the pond can change. There may be an optimal state, which permits to handle the situation in the best way (Madsen et al., 2009; Uwasu et al., 2012). Furthermore, if there are several ponds in series or in parallel, flow can be managed mutually among ponds. It is possible to optimize water allocation among several ponds to optimize the water management (Lund \& Guzman, 1999).

Hydropower solutions are feasible applications by using stormwater storage to reduce energy costs. These solutions take the advantage of power production based on its own available flow energy by water storage capacity, saving on the purchase of energy produced by fossil sources and contributing for the reduction of the greenhouse effect. In recent studies (Vieira \& Ramos, 2008; Ramos \& Ramos, 2009a; 2009b; Vieira \& Ramos, 2009), the option to use hydro energy source (combined or not with other renewable sources) seems to be a solution to mitigate the energy needs and to adapt urban zones to mitigate against overflow events. So, this new idea has the advantage of floods control and adaptation in different urban areas typology which can suddenly suffer fast and dangerous inundations.

DSSs can be used to optimize pond dimensions or operating rules. This is the goal of this paper. Some configurations are tested and optimized to control storm events and maximize energy production in hydropower plants.

\section{Simulation and Optimization Models: DHI Mike Basin and Bentley Pondpack}

\subsection{DHI MB Moldel}

Mike Basin (MB) is a model in which rivers and their main tributaries are represented by a network of branches and nodes. Branches represent individual stream sections and nodes represent confluences, diversions, locations where certain water activities may occur (municipal, industrial, reservoir and hydropower water uses), or important locations where model results are required. All information regarding the configuration of the flow simulation network, location of water users, reservoirs and intakes, and outlets of return flow are also defined.

MB is a powerful modeling tool for integrated river basin planning and management, which accommodates a catchment wide representation of water availability, sector water demands, multi-purpose reservoir operation, transfer/diversion schemes, and possible environmental constraints. 


\subsubsection{Components}

Catchments allow the inclusion of rainfall through the use of the Nedbør-Afstrømnings-Model (NAM model). In particular, catchments are used to define an upstream flow in river networks. The integration of the NAM model, which specifies the relationship between rainfall and runoff, is done through catchments. In this way, catchments incorporate climate characteristics such as precipitation or evapotranspiration depths data in the river network.

Reservoirs permit to manage water and to handle stormwater. Furthermore, they are used to introduce hydropower stations. For this paper, reservoirs are considered as retention ponds. Individual reservoirs or retention ponds can be used to simulate and optimize the performance and efficiency of reservoir operating rules to handle stormwater. Storage volumes, water levels and releases as a function of current water level, time of the year, water demand and energy production can be defined.

An important goal of this paper is to present an analysis of possible solutions to minimize flood events by using pond water storage volumes and to produce energy at the same time. This implies that the pond is not operated (there is always water release which depends only on the water level and on outlet capacity). This dry pond ("dry" because there may be no water in the pond) is defined by a table which contains the relationship between water levels, the corresponding stored volume and surface area. This table specifies the shape of the pond.

Characteristic levels have to be defined too to determine the behavior of the pond. These include bottom level, dam crest level and top of dead storage. To avoid that water level is above the dam crest level, a control level is defined, which is below the dam crest level and which permits the release of water if the pond inflows can be handled by the bottom outlet alone. An allocation rule is defined to specify water allocation among users according to water levels. In this case, water users are hydropower stations and water is released as long as there is water in the pond. The dry pond geometry is presented in Figure 1.

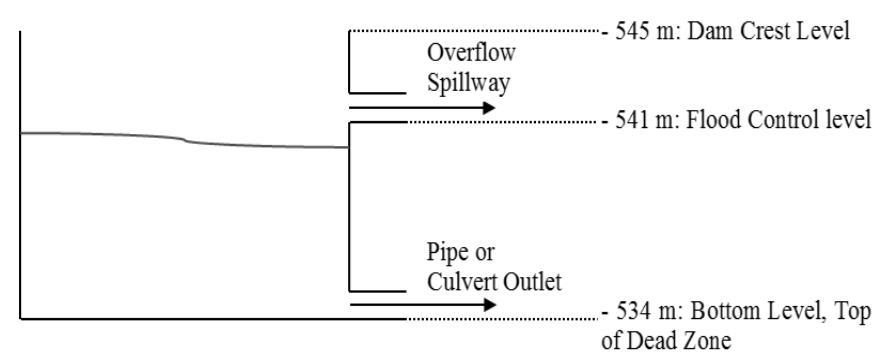

Figure 1. Dry pond shape

Hydropower stations presented in the model as hydropower nodes are supplied with water by channels. Flow capacity is a property of these channels. It limits the water flow through turbines and helps in the prevention of flood event occurrences. Hence it is possible to specify the installed capacity of turbines in the hydropower node, the minimum head difference for operations and the target demand, which defines what energy production is required.

\subsubsection{The NAM Model}

NAM is the rainfall-runoff (RR) module of the MB river-modelling system. It is a lumped, conceptual rainfall-runoff model, simulating overland flow, interflow and base flow. The RR module can either be applied independently or used to represent one or more contributing catchments that generate lateral inflows to a river network. It simulates the behavior of soil zones as parts of the hydrological cycle. It allows to model processes which generate flows at the catchment scale. Runoff is calculated from meteorological data (rainfall and evapotranspiration time series): running the rainfall-runoff model creates input catchment runoff time series files for the specified catchments. It takes into account the characteristics of the catchment which contribute to the transformation of rainfall into runoff: terrain characteristics such as soil occupation, vegetation and catchment slope.

In the NAM model, the soil is divided into four inter-connected zones: Surface storage zone, Root zone storage zone, Groundwater storage zone, Snow storage zone (optional). Parameters are used to define each zone of the soil and to characterize the exchange of water flows among them. In the NAM model, rainfall time series and evaporation time series are introduced to define an effective rainfall time series (rainfall depth values less 
evaporation depth values) and a runoff time series is generated. The total inflow generated with this model and a rainfall hyetograph has a total volume of $270077 \mathrm{~m}^{3}$. The model is defined to represent an impervious urban area of $0.05 \mathrm{~km}^{2}$.

\subsubsection{Optimization Tool}

The optimization model is based on a multi-criteria tool in which any model result can be included in an objective function. This function is used to determinate the best solution. It is an important tool which is useful to improve a situation without creating new components by streamlining the management of existing components. For instance, it permits to find best rule curves (Pareto curves) according to defined goals.

The objective of optimization is different to that of simulation. In a simulation, the inputs are specified and the model generates outputs. In an optimization, the outputs that are needed are defined and the model tries to find inputs values, which give the best response.

MB uses a nonlinear program optimization algorithm, which can be used to formulate any combination of minimum, maximum and goal attainment objectives. It is possible to choose parameters, which are added to yield the total (scalar) objective function. The objective function, $f$, is computed as:

$$
f(x)=\sum_{i=1}^{m} v_{j}\left(y_{j}-g_{j}\right)^{p_{j}}
$$

Where $x$ is the vector of variables to be optimized, $y_{j}$ is one of m MIKE BASIN simulation results, $g_{j}$ is a goal value for that result, $\mathrm{p}_{\mathrm{j}}$ is a power, and $\mathrm{v}_{\mathrm{j}}$ is a weight. The weight can be differentiated as a weight below a goal value and a weight beyond a goal value:

$$
v_{j}=\left\{\begin{array}{lll}
v_{j}^{-} & : & y_{j} \leq g_{j} \\
v_{j}^{-} & : & y_{j}>g_{j}
\end{array}\right.
$$

Table 1 shows how to set the goal, power and weight parameters for each type. Weights and powers determine the relative importance of every term in the overall objective function.

Table 1. Weights and powers in the objective function

\begin{tabular}{lllll}
\hline For a model result $\mathrm{y}_{\mathrm{j}}$, to..., set : & $\mathrm{g}_{\mathrm{j}}$ & $\mathrm{p}_{\mathrm{j}}$ & $\mathrm{v}_{\mathrm{j}}^{-}$ & $\mathrm{v}_{\mathrm{j}}^{+}$ \\
\hline Minimize it & 0 & 1 & $>0$ & $=\mathrm{v}_{\mathrm{j}}$ \\
Maximize it & 0 & 1 & $<0$ & $=\mathrm{v}_{\mathrm{j}}$ \\
Make it attain a goal $\mathrm{y}_{\mathrm{g}}$ & $\mathrm{y}_{\mathrm{g}}$ & 2,4, etc. & $>0$ & $=\mathrm{v}_{\mathrm{j}}$ \\
Make it exceed o goal $\mathrm{y}_{\mathrm{g}}$ & $\mathrm{y}_{\mathrm{g}}$ & 2,4, etc. & $>0$ & 0 \\
Make it remain below a goal $\mathrm{y}_{\mathrm{g}}$ & $\mathrm{y}_{\mathrm{g}}$ & 2,4, etc. & 0 & $>0$ \\
\hline
\end{tabular}

At each iteration, a new set-up of parameters to be optimized is tested and the objective function is calculated. Optimal set-up is found when the objective function is minimized.

\subsection{Bentley Pond Pack}

Bentley Pond Pack is an analysis tool, which permits to develop outlet rating curves and outlet structures, to perform interconnected pond routing and to handle divergent outfalls. In this research this model is used to design pond dimensions, outlet properties and pond configurations and catchments.

Pond Maker is an additional tool to help the design of ponds through a step-by-step process that provides constant feedback on how the design is progressing:

- $\quad$ Design scenario: it is possible to specify allowable pond outflow rates;

- Storage estimate: according to the inflow and the allowable outflow, it estimates the pond volume required to store water;

- Pond dimensions: according to the estimation of the volume storage, it is possible to generate pond dimensions; 
- Outlet design: this step permit to compute a target rating curve based on storage requirements and allowable outflow rates;

- $\quad$ Routing: it processes full routing results to report maximum outflow, storage, water surface elevation. It permits to ensure that all objectives are reached in the whole model.

This model is supported by the Soil Conservative Service Runoff Curve Number (SCS CN).

The SCS CN is calculated with the following formula using rainfall and runoff:

$$
Q=\frac{(P-0.2 S)^{2}}{(P+0.8 S)}
$$

where $\mathrm{Q}$ is the total runoff depth in $\mathrm{mm}, \mathrm{P}$ is the total rainfall depth in $\mathrm{mm}$ and $\mathrm{S}$ is the total soil volume storage estimated with the following formula:

$$
S=\frac{1000}{C N}-10
$$

where $\mathrm{CN}$ is the curve number.

A SCS CN standard of 100 is used. This number corresponds to a totally impervious urban area, such as the NAM model of the catchment defined in MB. The total volume of the inflow generated by Pond Pack with this parameter, an area of $0.05 \mathrm{~km}^{2}$ and the same rainfall time hyetograph defined in $\mathrm{MB}$, is $277067 \mathrm{~m}^{3}$ which is quite similar to those found with MB. It permits to design ponds in Pond Pack and to use parameters found directly in MB.

\section{Methodology}

The principal parameter to be optimized is the energy produced by hydropower systems. The power target demand is optimized to get the maximum amount of electricity. The production of energy from the second hydropower plant is harmonized with the electricity consumption demand (Figure 2) in order to produce more energy when the electricity consumption is higher.

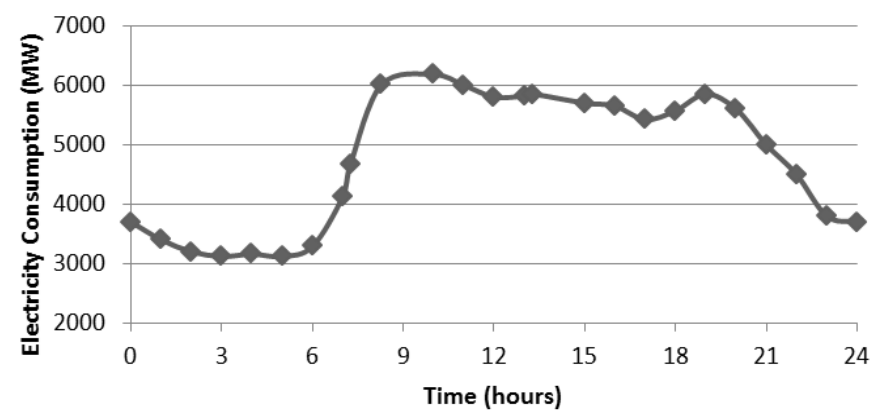

Figure 2. Electricity consumption curve

Producing more energy when the demand is higher is profitable because the peak demand electricity tariffs are higher too. Therefore, a target demand time series is created with the same shape as that of the electricity consumption curve.

Even if the system efficiency is not taken into account in the model, the discharge must be more or less constant in both turbines in order to avoid any significant efficiency variation.

Hydropower1 has a target demand time series with a constant value so that this defines the parameter (TD1) which can be modified to find an optimal functioning point and which characterizes Hydropowerl target demand time series. Hydropower2 has a target demand adapted to energy consumption showed previously, the parameter chosen to calibrate the curve is the maximum value of generated energy to be produced (TD2). This way is the simplest way to optimize a time series, which does not have a single value. A parameter is defined to characterize this time series, and optimal value for this parameter is found through simulation. It appears that because of the influence of TD2 it is not easy to optimize a time series which contains different values for each time step, and this would require an optimization for each time step. 
For different tested TD2 values, the TD1 optimal value is found (TD1Opt). By considering the TD2 influence on the production of energy, it is possible to find the TD2 optimal value (TD2Opt). In this way, the optimal set-up (TD1Opt; TD2Opt) which permits to produce the highest amount of energy is obtained.

\section{Case Studies and Results}

\subsection{A Single Pond}

The configuration of a single pond is presented in Figure 3. At first, the pond dimensions are chosen in order to store all the water from the inflow.

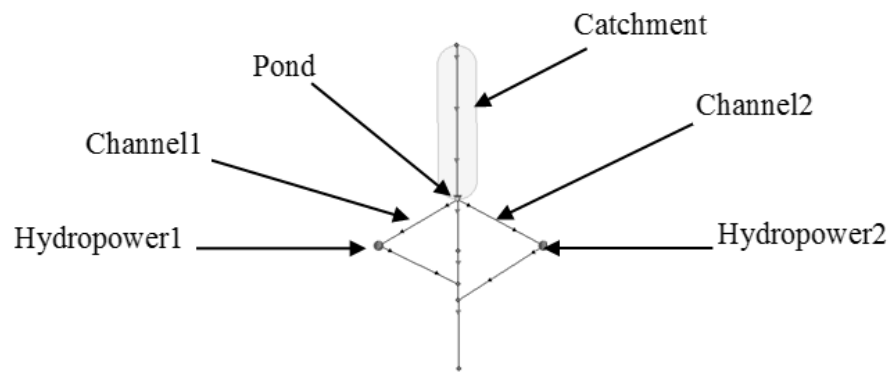

Figure 3. A single pond configuration

The targeted outflow is $1.5 \mathrm{~m}^{3} / \mathrm{s}$ because it is the required water release in two days (duration chosen to release all the water). Table 2 presents the parameters chosen for this configuration and Figure 4 shows the produced electricity amount.

Table 2. Parameters used for a single pond

\begin{tabular}{ll}
\hline Parameters & Value \\
\hline Channel1 flow capacity (m3/s) & 0.5 \\
Channel2 flow capacity (m3/s) & 1 \\
Hydropower1 minimal TD1 (MW) & 0.0125 \\
Hydropower2 minimal TD2 (MW) & 0.044 \\
\hline
\end{tabular}

The optimal set-up is TD1 $=0.0125 \mathrm{MW}$ and TD2 $=0.044 \mathrm{MW}$, which are the smallest values for each parameter. The curves obtained with this set-up are presented in Figure 5. These figures show the electricity production follows the target demand as long as there is enough water in the pond. When the water level is not enough to ensure the pressure required by the turbines, the discharge flows through the turbines increase to their maximum values. Electricity production depends on the head difference and discharge. If there is not enough head difference to reach target production, the discharge required to produce energy increases in order to offset. 


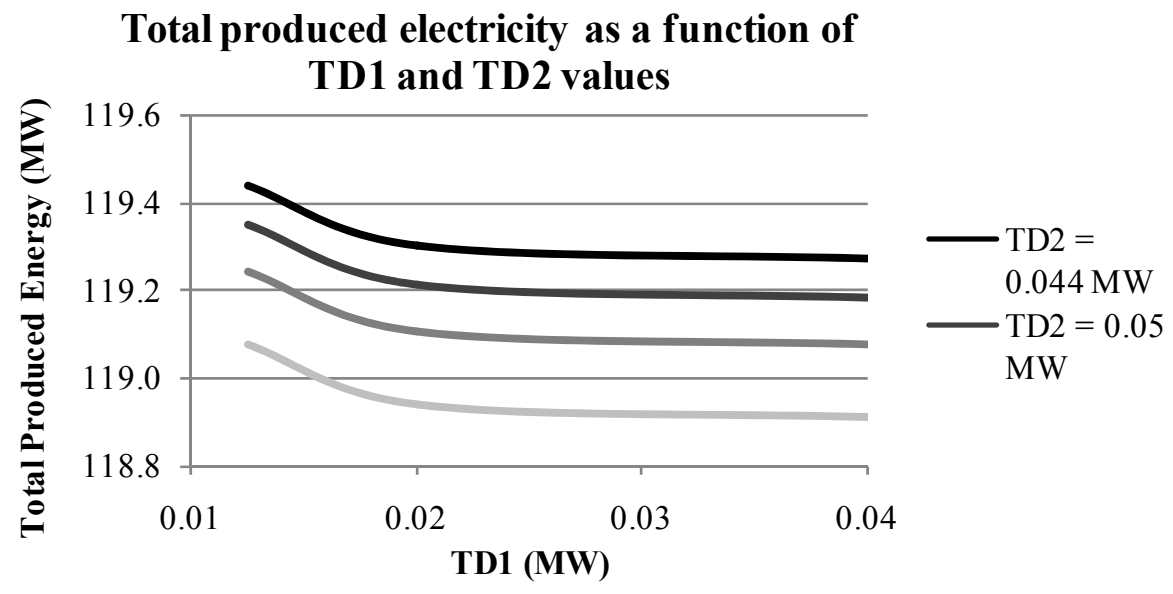

Figure 4. Produced electricity results for a single pond

\section{Hydropower1 generated electricity}

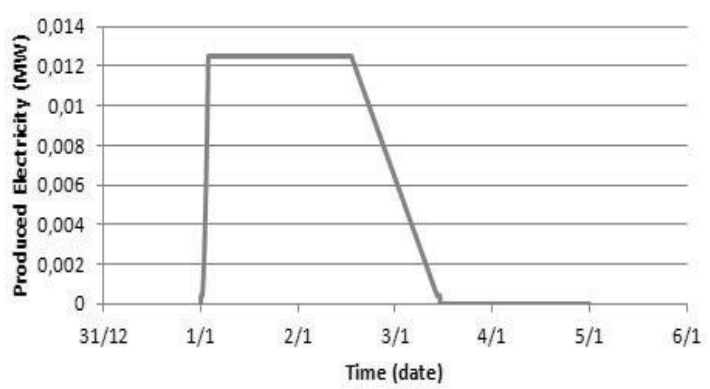

Hydropower2 generated electricity

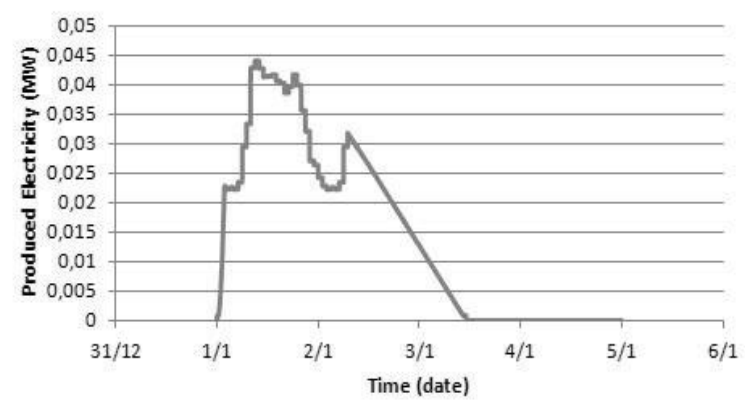

Pond water level

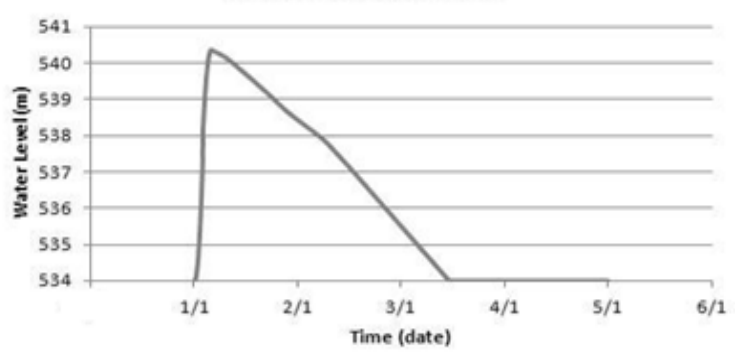

Figure 5. Results for a single pond

Secondly, the rainfall lasts for 4 hours but the release lasts for almost 58 hours. Maximum outflow is reached $\left(1.5 \mathrm{~m}^{3} / \mathrm{s}\right)$ at the beginning of the rainfall when runoff is maximum and at the end of the release when discharge through channels increases to compensate for the lack of head difference.

Finally, in this configuration $119.49 \mathrm{MW}$ were produced in total with a peak production of $56.5 \mathrm{~kW}$ during periods in which there is a peak demand for electricity. Complementary simulations show that this is not the optimal production that can be obtained because for smaller TD2 values, there is a slower release which produces more energy with a smaller instantaneous generated power. But in this case, the flow through the turbines is smaller than $40 \%$ of the nominal operating point and a significant efficiency drop is noticed. Furthermore, the release of the water is done in a longer time than the time expected ( 2 days). The duration of the release is an important criterion because if several rainfalls are expected in a short time, water must be released in a time as short as possible.

In the case in which there is a single pond, appropriate pond sizes found are the same as those defined previously. The pond area, the inflow from the catchment and the outflow targeted are the same as those defined. The same total pond depth is obtained. However, Bentley PondPack permits to design outlet properties. An orifice of $0.5 \mathrm{~m}$ is obtained. Because the pond sizes are the same as the ones defined, optimization gives the same results. 


\subsection{Two Ponds in Parallel}

The configuration of two ponds in parallel is presented in Figure 6. Runoff used for one dry pond is divided into two runoffs for each catchment. Therefore, the total stored water volume is divided by two and the target outflow is $0.78 \mathrm{~m}^{3} / \mathrm{s}$. Because of the smaller inflows, the retention ponds are defined with the half of the area used for the case with a single pond.

Because of the similarity of the problem between the two river branches, Hydropower1 and Hydropower3 have the same target demand time series (defined by TD1 in the same way as previously). In the same way, Hydropower2 and Hydropower4 have the same target demand time series (characterized by TD2). Parameters used are presented in Table 3.

The corresponding results are presented in Figure 7. It seems that the best set-up to produce most energy is again the minimum allowed values for TD1 and TD2: TD1 $=0.006 \mathrm{MW}$; TD2 $=0.025 \mathrm{MW}$. The total produced electricity in this case is $119.05 \mathrm{MW}$, which equals the amount of electricity produced in the case in which there is a single pond. However, in this case smaller ponds are used because the area of each pond is $0.02 \mathrm{~km}^{2}$.

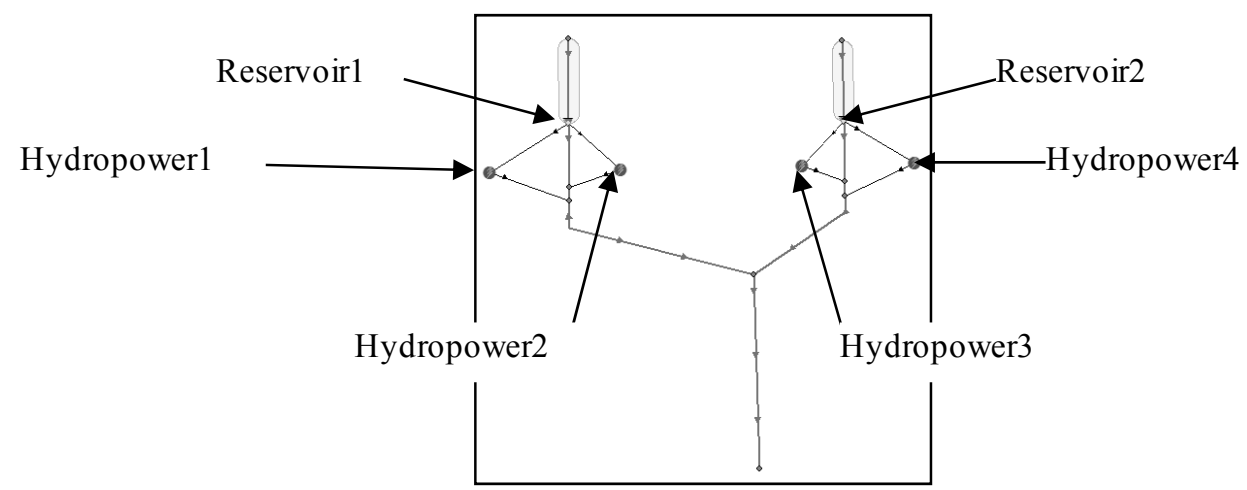

Figure 6. Two ponds in parallel configuration

Table 3. Characteristic parameters for two ponds in parallel

\begin{tabular}{ll}
\hline Parameters & Value \\
\hline Channel1 and Channel3 flow capacity $\left(\mathrm{m}^{3} / \mathrm{s}\right)$ & 0.26 \\
Channel2 and Channel4 flow capacity $\left(\mathrm{m}^{3} / \mathrm{s}\right)$ & 0.52 \\
Hydropower1 and Hydropower3 minimal TD1 (MW) & 0.006 \\
Hydropower2 and Hydropower4 minimal TD2 (MW) & 0.025 \\
\hline
\end{tabular}

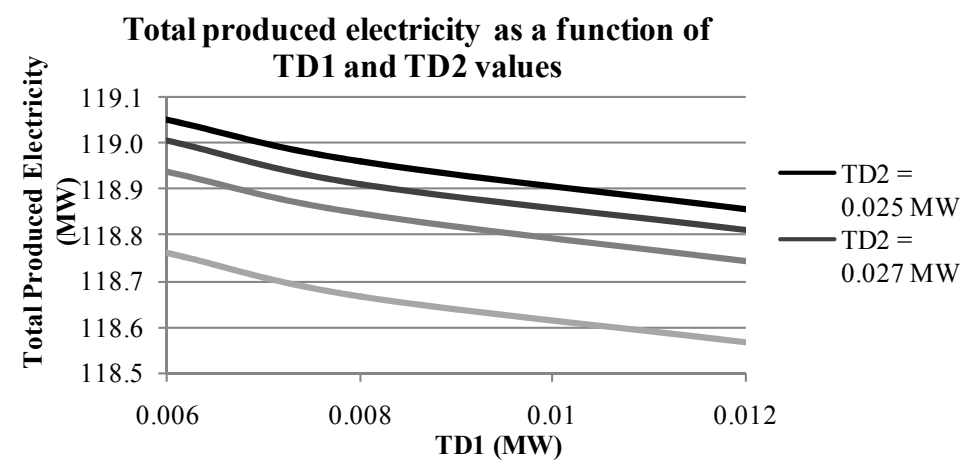

Figure 7. Produced electricity results for two ponds in parallel 
Hydropower1 and Hydropower3 have the same energy production and the same flows, as well as Hydropower2 and Hydropower4 also have the same energy production and operation in the same conditions. Water levels are equals in both ponds (Figure 8). Releases last for almost 57 hours with a maximum flow of $1.56 \mathrm{~m}^{3} / \mathrm{s}$.

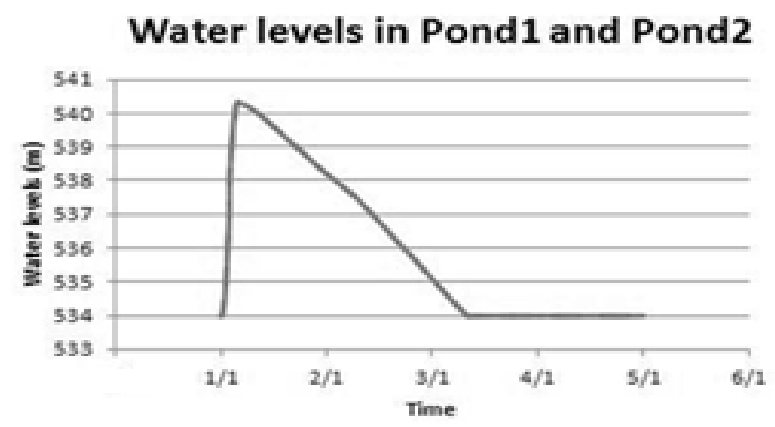

Figure 8. Water levels curves for two ponds in parallel

Because of the equivalence of each river branch, each one may be considered as a catchment with a single pond. For the same reasons as in the study about the design of a single pond, after the design of both ponds, optimization results give the same results.

\subsection{Two Ponds in Series}

The configuration of two ponds in series is presented in Figure 9. Firstly, ponds, channels and hydropower stations are defined as the single pond in the first case study. Parameters used are presented in Table 4. The corresponding results are presented in Figure 10. In this configuration, the optimal set-up (TD1 $=0.0125 \mathrm{MW}$; $\mathrm{TD} 2=0.044 \mathrm{MW}$ ) to produce maximum electricity permits to get $123.2 \mathrm{MW}$. As expected, this amount of energy is bigger than the one obtained in the case in which there is a single pond because two turbines are added. But Pond 2 and the water release from Pond 2 are not well designed because there is no stored water stored in Pond2 and the hydropower target demands are not reached (Figure 11).

Table 4. Parameters used in MB - Two ponds in parallel

\begin{tabular}{lc}
\hline \multicolumn{1}{c}{ Parameters } & Value \\
\hline Channel1 and Channel3 flow capacity $\left(\mathrm{m}^{3} / \mathrm{s}\right)$ & 0.5 \\
Channel2 and Channel4 flow capacity $\left(\mathrm{m}^{3} / \mathrm{s}\right)$ & 1 \\
Hydropower1 and Hydropower3 minimal TD1 (MW) & 0.0125 \\
Hydropower2 and Hydropower4 minimal TD2 (MW) & 0.044 \\
\hline
\end{tabular}

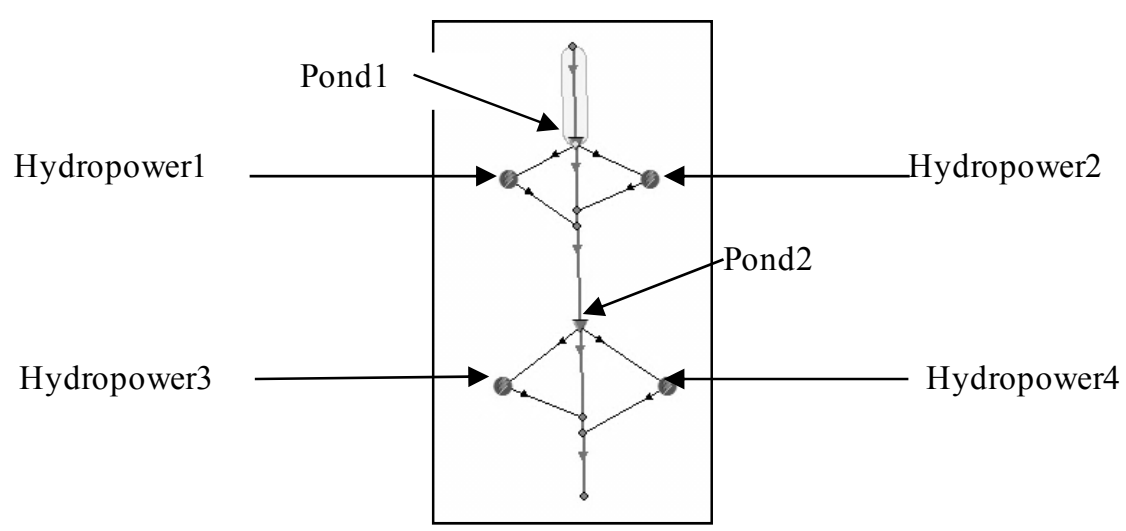

Figure 9. Two ponds in series configuration 


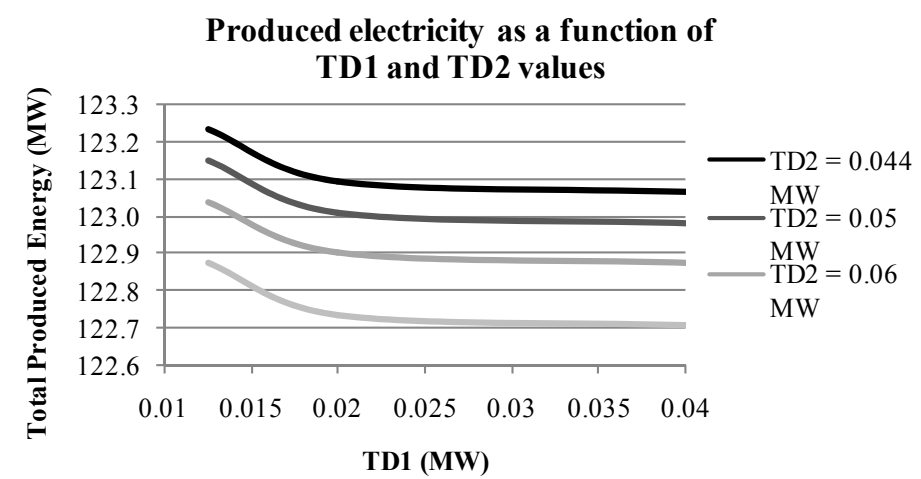

Figure 10. Produced electricity results for two ponds in series

Water levels in Pond1 and Pond2

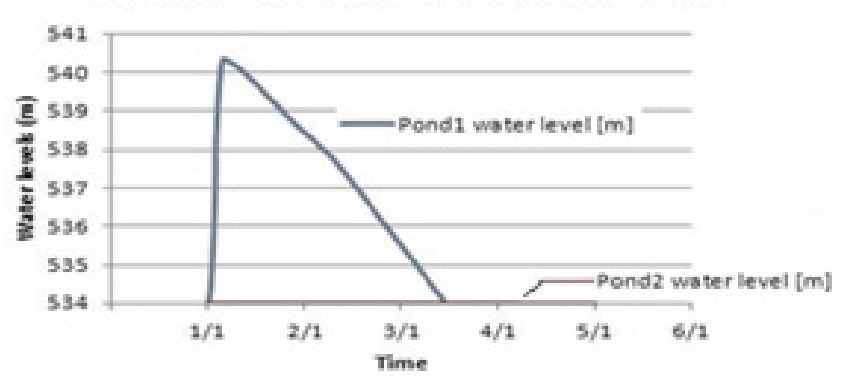

Figure 11. Water levels curves for the two ponds in series

In this case, the model permits to redefine the pond dimensions. The parameters obtained are presented in Table 5 .

Table 5. Parameters from Bentley PondPack - Two ponds in series

\begin{tabular}{lll}
\hline Parameters & Pond 1 & Pond 2 \\
\hline Area $\left(\mathrm{km}^{2}\right)$ & 0.04 & 0.01 \\
Total Depth (m) & 6.79 & 4.8 \\
Orifice Diameter (m) & 0.6 & 0.6 \\
Computed Peak Outflow $\left(\mathrm{m}^{3} / \mathrm{s}\right)$ & 1.82 & 1.39 \\
Computed Max Water Elevation $(\mathrm{m})$ & 6.16 & 3.74 \\
\hline
\end{tabular}

Table 6. Channels' parameters and target demand requirements for two ponds in series

\begin{tabular}{lll}
\hline Pond1 & Channel1 & Channel2 \\
\hline Capacity $\left(\mathrm{m}^{3} / \mathrm{s}\right)$ & 0.61 & 1.22 \\
TD1min $(\mathrm{MW})$ & 0.014 & \\
TD2min $(\mathrm{MW})$ & & 0.053 \\
\hline Pond2 & Channel1 & Channel2 \\
\hline Capacity $\left(\mathrm{m}^{3} / \mathrm{s}\right)$ & 0.46 & 0.92 \\
TD1min $(\mathrm{MW})$ & 0.014 & \\
TD2min $(\mathrm{MW})$ & & 0.054 \\
\hline
\end{tabular}


In the MB model, pond dimensions and channel flow capacities are redefined to meet these results. Because channel flow capacities are changed, new minimal target demand parameters have to be found to insure at least $40 \%$ of the maximum flow in the channel (to avoid efficiency reduction). According to the optimization scheme used, the parameters obtained are presented in Table 6. The optimal set-up found (minimal target demand for each hydropower station) with $\mathrm{MB}$ is tested with these new parameters. A total generated electricity of 165.54 MW is obtained. The first optimization with MB permits to obtain 123.23 MW.

Furthermore, in the first optimization, there is no water storage in the Pond2. After PondPack design, Pond2 stores a part of the water which permits to get a higher head difference and energy production is increased (Figure 12).

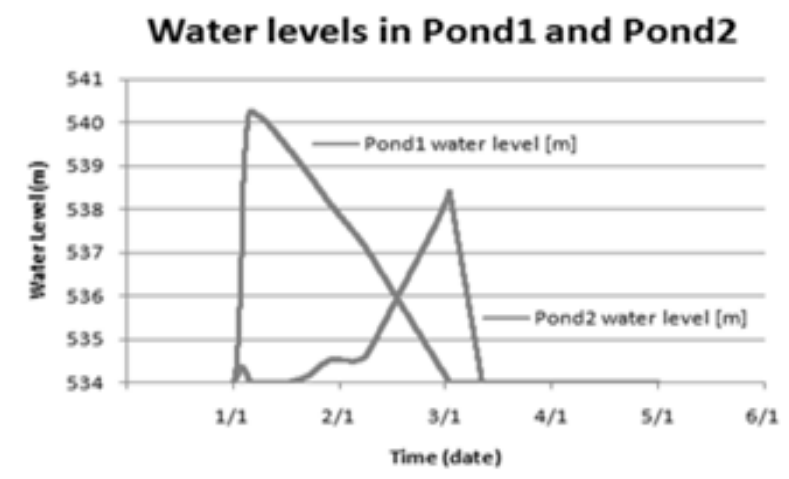

Figure 12. Water level curves for two ponds in series

Bentley PondPack tool permits to improve the set-up of parameters for the ponds and channels. With this better design, better results are obtained in this case study.

\subsection{Two Ponds in Series with Two Catchments}

The configuration of two ponds in series with two catchments is presented in Figure 13. Each catchment has an area of $0.025 \mathrm{~km}^{2}$ and the total runoff is divided by two. The first reservoir receives and manages half of the total runoff and it has an area of $0.02 \mathrm{~km}^{2}$. The second reservoir can accept the total runoff and has an area of 0.02 $\mathrm{km}^{2}$.Different model characteristics are gathered in Table 7.

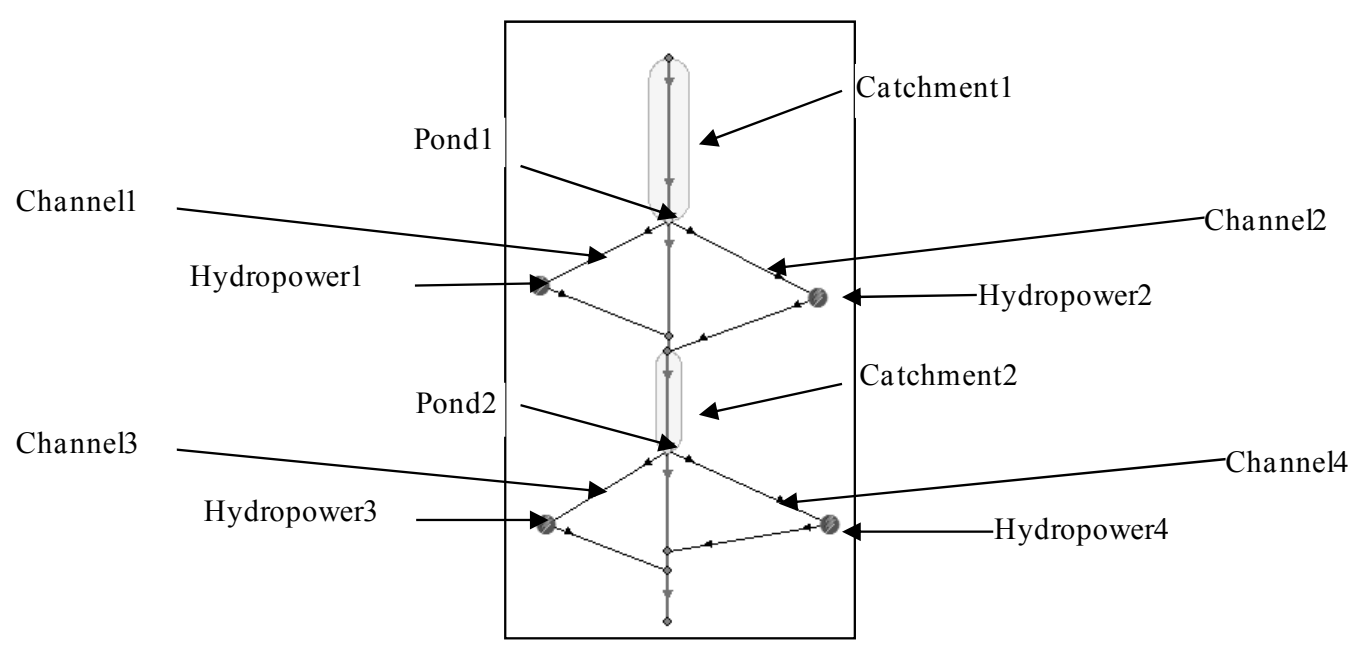

Figure 13. Two ponds in series with two catchments configuration 
Table 7. Parameters used in the case with two ponds in series and two catchments

\begin{tabular}{ll}
\hline Parameters & Values \\
\hline Channel1 flow capacity $\left(\mathrm{m}^{3} / \mathrm{s}\right)$ & 0.26 \\
Channel2 flow capacity $\left(\mathrm{m}^{3} / \mathrm{s}\right)$ & 0.52 \\
Channel3 flow capacity $\left(\mathrm{m}^{3} / \mathrm{s}\right)$ & 0.5 \\
Channel4 flow capacity $\left(\mathrm{m}^{3} / \mathrm{s}\right)$ & 1 \\
Hydropower1 minimal target demand (MW) & 0.006 \\
Hydropower2 minimal target demand (MW) & 0.025 \\
Hydropower3 minimal target demand (MW) & 0.0115 \\
Hydropower4 minimal target demand (MW) & 0.028 \\
\hline
\end{tabular}

Both reservoirs are designed as previously and keep the same operating rules. A parameter is defined for each hydropower target demand time series to help to find an optimal set-up: TD1 (Hydropower1), TD2 (Hydropower2), TD1bis (Hydropower3), TD2bis (Hydropower4).

Firstly, the influence of TD1bis and TD2bis is evaluated (Figure 14).

(a)

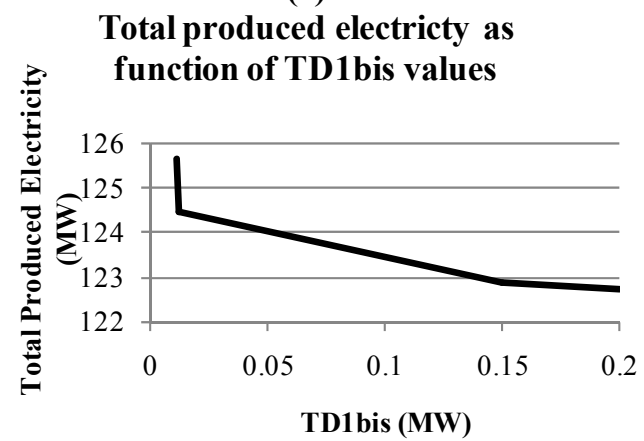

(b)

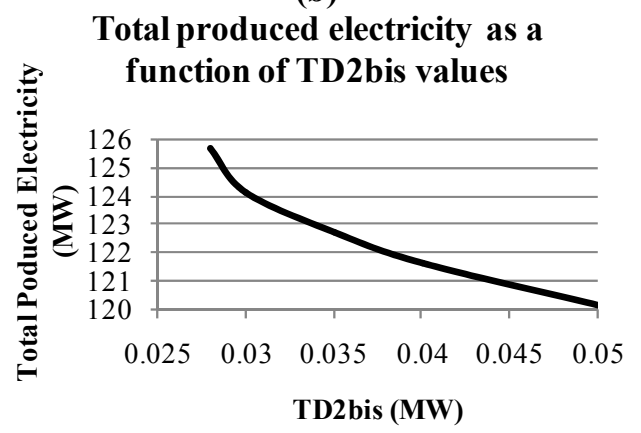

Figure 14. TD1bis influence (a) and TD2bis influence (b) on the produced energy

As previously, the optimal set-up for Hydropower3 and Hydropower4 target demand parameters are minimum values for each one. The minimum values are kept for next simulations that show the influence of TD1 and TD2 on the produced energy.

The optimization parameters have to be changed because of the shape of the curve describing the influence of parameters on the energy production. From a threshold, TD1 has no influence any more on the produced energy which is maximized. It is possible to change optimization restrictions.

The parameters are defined as follows:

- Finite Difference factor for numerical gradient: 1E-10 (choosing a small value permits to reduce perturbations in the tested variables. These perturbations are done to test other variables values)

- Stagnation: 0.1 (if the flatness is less than this value during $5 * \mathrm{n}$ iterations, $\mathrm{n}$ being the number of variables optimized, optimization ends)

The Finite difference factor is reduced to minimize variables perturbations. When flatness does not vary, according to the defined stagnation threshold, optimization stops and the last tested variables are defined as final results. Little perturbations are defined in order to stay close to the first optimum met. These changes permit to find a "good enough" optimum. It means that found optimum may not be the global optimum because optimization may stop before reaching the global optimum but is very close. In the following table and graph, TD1 and TD2 optimization results are presented in Table 8 and Figure 15. 
Table 8. Final results for two ponds in series with two catchments

\begin{tabular}{cccccccccc}
\hline $\begin{array}{c}\text { TD1 } \\
(\mathbf{M W})\end{array}$ & $\begin{array}{c}\text { TD2 }=\mathbf{0 . 0 2 5} \\
\mathbf{M W}\end{array}$ & $\begin{array}{c}\text { TD1 } \\
(\mathbf{M W})\end{array}$ & $\begin{array}{c}\text { TD2 }=\mathbf{0 . 0 3} \\
\mathbf{M W}\end{array}$ & $\begin{array}{c}\text { TD1 } \\
(\mathbf{M W})\end{array}$ & $\begin{array}{c}\text { TD2 }=\mathbf{0 . 0 3 5} \\
\mathbf{M W}\end{array}$ & $\begin{array}{c}\text { TD1 } \\
(\mathbf{M W})\end{array}$ & $\begin{array}{c}\text { TD2 }=\mathbf{0 . 0 4} \\
\text { MW }\end{array}$ & $\begin{array}{c}\text { TD1 } \\
(\mathbf{M W})\end{array}$ & $\begin{array}{c}\text { TD2 }=\mathbf{0 . 0 5} \\
\text { MW }\end{array}$ \\
\hline 0.006 & 125.640919 & 0.006 & 130.420928 & 0.006 & 133.033942 & 0.006 & 134.711182 & 0.006 & 136.938746 \\
0.01 & 136.666848 & 0.01 & 140.256364 & 0.01 & 142.235601 & 0.01 & 143.757688 & 0.01 & 145.840599 \\
\hline $\begin{array}{c}\text { TD1Opt } \\
=\mathbf{0 . 0 1 7 3}\end{array}$ & $\mathbf{1 4 0 . 6 4 7 6 0 2}$ & $\begin{array}{c}\text { TD1Opt } \\
\mathbf{= 0 . 0 1 5 3}\end{array}$ & $\mathbf{1 4 3 . 5 3 0 9 0 3}$ & $\begin{array}{c}\text { TD1Opt } \\
=\mathbf{0 . 0 1 4 7}\end{array}$ & $\mathbf{1 4 5 . 3 6 3 5 4}$ & $\begin{array}{c}\text { TD1Opt } \\
=\mathbf{0 . 0 1 4 4}\end{array}$ & $\mathbf{1 4 6 . 7 8 0 5 4 7}$ & $\begin{array}{c}\text { TD1Opt } \\
=\mathbf{0 . 0 1 4 1}\end{array}$ & $\mathbf{1 4 8 . 6 6 1 0 5 6}$ \\
\hline 0.1 & 140.647602 & 0.1 & 143.530903 & 0.1 & 145.36354 & 0.1 & 146.780547 & 0.1 & 148.661056 \\
\hline
\end{tabular}

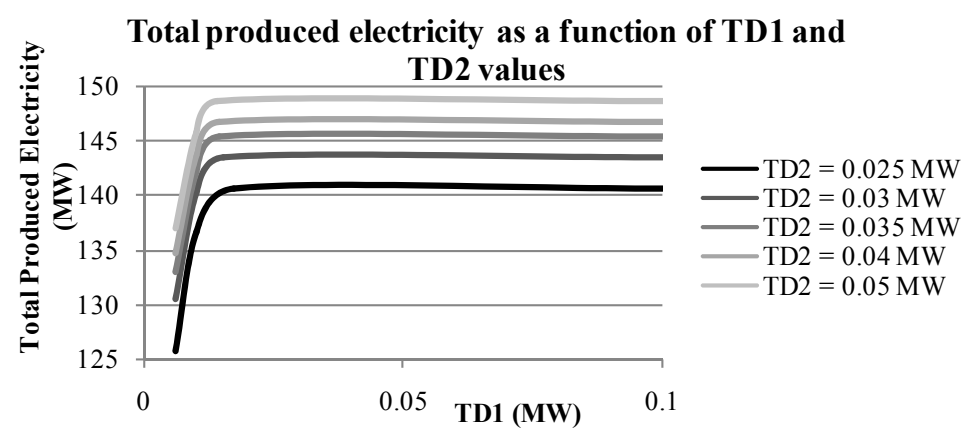

Figure 15. Produced electricity results for two ponds in series with two catchments

The evolution of produced energy according to TD1 and TD2 is different than what results have shown until now. The influence of TD1 and TD2 is inverted. The higher they are the more energy is produced. Produced electricity by each couple of turbines is presented in Figures 16 and 17.

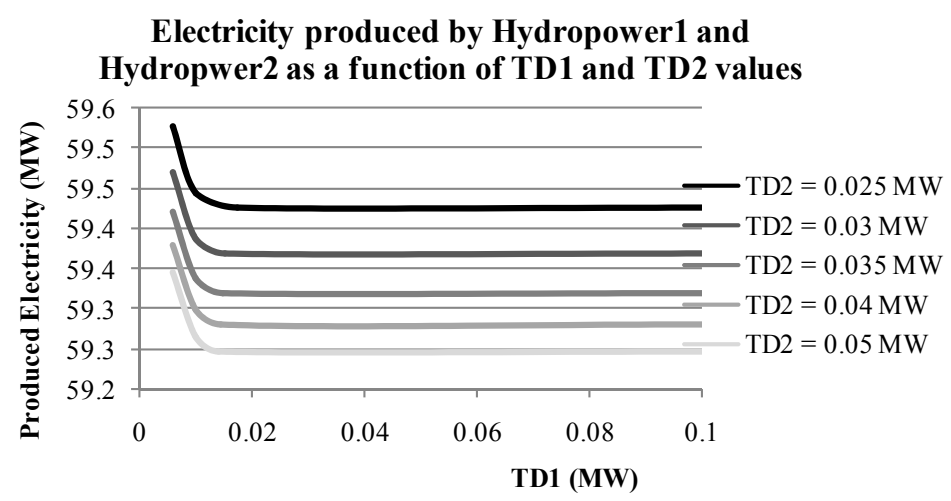

Figure 16. Produced electricity results (Hydropower1+Hydropower2)

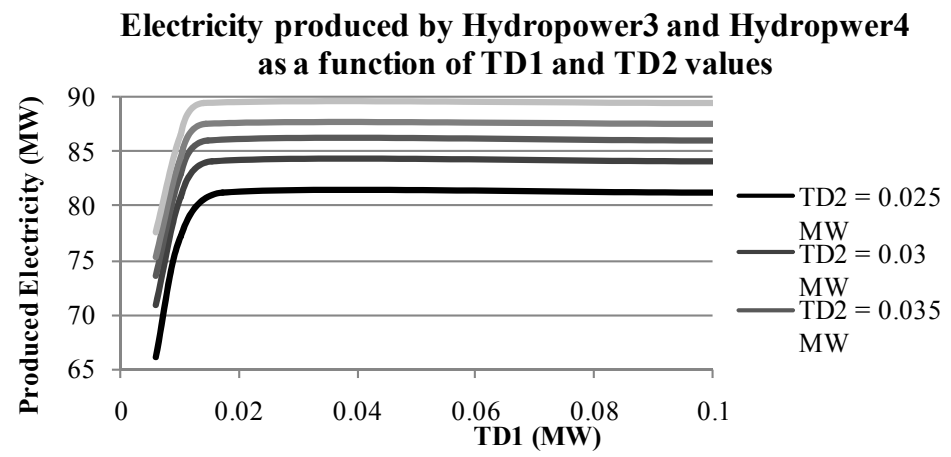

Figure 17. Produced electricity results (Hydropower3+Hydropower4) 
TD1 and TD2 have the same influence than previously for the first couple of turbines. But, when TD1 and TD2 increase, produced energy in Hydropower1 and Hydropower2 decreases and produced energy in Hydropower3 and Hydropower4 increases. By increasing the target demand, water demand increases. This means that if the target demand increases from the first reservoir, inflow in the second reservoir is higher (until the threshold values of TD1 and TD2 are reached). If the inflow is bigger, the water level decreases slowly, ensuring a better head difference for both turbines during a longer time and permitting to release water for a longer time too. Finally, in this special case it seems reasonable to maximize TD1 and TD2 in order to supply the maximum inflow for Hydropower3 and Hydropower4 (Figure 18).

These observations reveal a new trend and show that the second couple of turbines and channels are not well-designed because they always work with maximum channel flow capacities and do not reach target demand.

The design of both ponds permits to find the parameters presented in Table 9. Because the outflows are changed, new parameters have to be considered (Table 10).
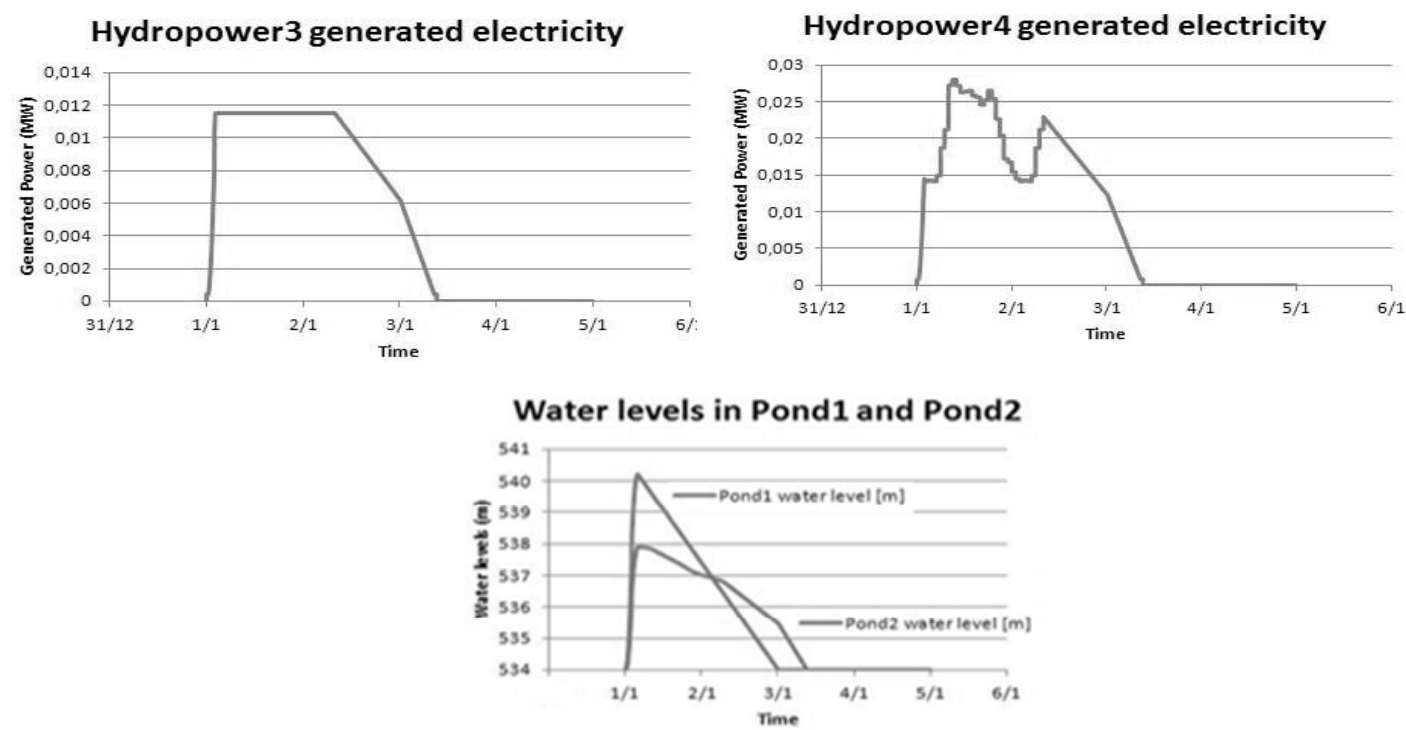

Figure 18. Results for two ponds in series with two catchments

Table 9. Characteristic parameters for two ponds in series with two catchments

\begin{tabular}{lll}
\hline Parameters & Pond 1 & Pond 2 \\
\hline Area $\left(\mathrm{km}^{2}\right)$ & 0.02 & 0.02 \\
Total Depth $(\mathrm{m})$ & 7.15 & 7.59 \\
Orifice Diameter $(\mathrm{m})$ & 0.4 & 0.55 \\
Computed Peak Outflow $\left(\mathrm{m}^{3} / \mathrm{s}\right)$ & 0.82 & 1.55 \\
Computed Max Water Elevation $(\mathrm{m})$ & 6.21 & 6.27 \\
\hline
\end{tabular}

Table 10. Channels' parameters and target demand requirements for two ponds in series with two catchments

\begin{tabular}{lll}
\hline Pond1 & Channel1 & Channel2 \\
\hline Capacity $\left(\mathrm{m}^{3} / \mathrm{s}\right)$ & 0.27 & 0.54 \\
\hline Pond2 & Channel1 & Channel2 \\
\hline Capacity $\left(\mathrm{m}^{3} / \mathrm{s}\right)$ & 0.5 & 1 \\
TD1min $(\mathrm{MW})$ & 0.0115 & \\
TD2min $(\mathrm{MW})$ & & 0.028 \\
\hline
\end{tabular}


Target demand parameters for Pond1 are obtained during optimization. TD2 is chosen to maximize flow through Hydropower2 as it is in first MB optimization. TD1 is obtained with the MB optimization tool. Finally, TD1 = $0.0141 \mathrm{MW}$ and TD2 $=0.05 \mathrm{MW}$. The total produced electricity is $293.81 \mathrm{MW}$. To compare, before the design of both ponds the total produced electricity is $148.66 \mathrm{MW}$. This step permits to increase the production by $50.5 \%$. The inflow is managed without any over flooding even if new pond dimensions are smaller and water levels quite similar (bottom graph of the Figure 18).

\section{Conclusions}

The optimization of energy production based on storm water storage in Alcântara zone is analysed through pond dimensions by optimizing target demand time series. Different configurations such as a single pond, two ponds in parallel or two ponds in series are studied.

Evidence suggests that only some configurations (single pond and two ponds in series with two catchments) are more suitable to produce energy. Particularly, in the last case (two ponds in series with two catchments) with properly designed ponds, the production of energy for the case study was $293.81 \mathrm{MW}$, whereas in the simple case (a single pong) the maximum production obtained was $119.49 \mathrm{MW}$.

Furthermore, pond design optimization was sized to produce the best energy solution. In the last case, an important improvement is done by reducing the second pond dimensions and redefining the release capacities for both ponds.

\section{Acknowledgments}

The authors would like to acknowledge CEHIDRO (Hydraulic Research Centre from the Civil Engineering Department of Instituto Superior Técnico (IST) - Technical University of Lisbon) and the research project EU HYLOW from the EU Seventh Framework Program for Research and Technological Development (Grant no. 212423), which contributed to the development of the research presented in this paper.

\section{References}

APFM, WMO, \& GWP. (2008). Reservoir Operations and Managed flows. The Associated Programme on Flood Management, the World Meteorological Organization (WMO) and the Global Water Partnership (GWP).

Bethers, U., \& Sennikovs, J. (2009). Ensemble modelling of impact of climate change on runoff regime of Latvian rivers. In proceedings of the $18^{\text {th }}$ World IMACS/MODSIM Congress, Australia, 13-14 July.

DHI. (2008). Water \&Environment Inc. and Lane Council of Governments. McKenzie River MIKE BASIN Model.

Giang, N. T., \& Phuong, T. A. (2010). Calibration and verification of a hydrological model using event data. Journal of Science, Earth Sciences, 26, 64-74.

King, S. (2004). Rainfall-Runoff Modelling report for the Upper Salmon and East Fork Salmon River Basins. DHI project Number: 4021.252 .

Lund, J. R., \& Guzman, J. (1999). Some Derived Operating Rules for Reservoirs in series or in Parallel. Journal of Water Resources Planning and Management, 125(3), 143-153. http://dx.doi.org/10.1061/(ASCE)0733-9496(1999)125:3(143)

Madsen, H., Richaud, B., \& Pedersen, C. B. (2009). A Real-Time Inflow Forecasting and Reservoir Optimization System for Optimizing Hydropower Production. Waterpower XVI.

Meadows, M. E., Walski, T. M., Barnard, T. E., \& Durrans, S. R. (2002). Computer Applications in Hydraulic Engineering (5th ed.). Publisher: Haestad Methods Inc.

Oliveira, R. P., \& Loucks, D. P. (1997). Operating rules for multi-reservoirsystems. Water Resources Research, 33(4), 839-852. http://dx.doi.org/10.1029/96WR03745

Orlob, G. (1992). Water Quality Modeling for Decision Making. Journal of Water Resources Planning and Management, 118(3), 295-307. http://dx.doi.org/10.1061/(ASCE)0733-9496(1992)118:3(295)

Ramos, H. M., Mello, M., \& De, K. P. (2010). Clean power in water supply systems as a sustainable solution: from planning to practical implementation. Water Science \& Technology: Water Supply-WSTWS, 10(1), $39-49$.

Ramos, J. S., \& Ramos, H. M. (2009a). Solar powered pumps to supply water for rural or isolated zones: A case study. Energy for Sustainable Development, 13(3), 151-158. 
Ramos, J. S., \& Ramos, H. M. (2009b). Sustainable application of renewable sources in water pumping systems: optimised energy system configuration. Energy Policy, 37(2), 633-643.

Thu, V. U. T., \& Tingsanchali, T. (2010). Flood hazard and risk assessment of Hoang Long River basin, Vietnam. In proceedings of the International MIKE by DHI Conference, 2010.

Wurbs, R. A. (2005). Civil Comparative Evaluation of Generalized River/Reservoir System Models. Texas Water Resources Institute.

Uwasu, M., Hara, K., Yabar, H., \& Zhang, H. (2012). Analysis of Energy Productivity and Determinant Factors: A Case Study of China's Provinces. Journal of Sustainable Development, 5(6), 1-9.

Yeh, William W-G. (1985). Reservoir Management andOperationsModels: A Stateof-the-ArtReview. Water Resources Research, 21(12), 1797. http://dx.doi.org/10.1029/WR021i012p01797

Vieira, F., \& Ramos, H. M. (2008). Hybrid solution and pump-storage optimization in water supply system efficiency: A case study. Energy Policy, 36(11), 4142-4148.

Vieira, F., \& Ramos, H. M. (2009). Optimization of operational planning for wind/hydro hybrid water supply systems. Renewable Energy, 34(3), 928-936. 